\title{
Status Epilepticus Treated by Intravenous Infusions of Thiopentone Sodium
}

\author{
ALLAN S. BROWN,* M.B., CH.B., F.F.A. R.C.S., D.A. ; JEAN M. HORTON,* M.B., CH.B., F.F.A. R.C.S., D.A.
}

Brit. med. F., 1967, 1, 27-28

Status epilepticus is encountered relatively infrequently in neurosurgical practice. As would be expected, its greatest frequency is found in epileptic colonies and the realms of general practice. From time to time such patients may be referred to the anaesthetist and his advice sought. Because of the relative infrequency with which such patients are seen, treatment is variable and not often reported. For that reason the experience of treating 117 such patients during the last 16 years is described.

Status developing in a patient already suffering from epilepsy is less surprising than the sudden onset of this condition after trauma or infection in a hitherto normal subject, and there is a tendency to attribute epilepsy to such factors as cortical thrombosis, scarring, or the escape of epileptogenic drugs from an abscess cavity. Such factors may be no more than a precipitating agency, for if the status is brought under control for 12 to 24 hours treatment can usually be discontinued without fear of recurrence.

In a review of factors influencing the incidence of epilepsy after brain wounds, Russell and Whitty (1952) suggest that, so far as the late development of epilepsy is concerned, there may be a disturbance of the normal balance of two equally important factors, one tending to provoke a fit and the other to inhibit it. The occurrence of epilepsy would be determined by which factor was the more affected.

This argument cannot be directly applied to the cause of epilepsy occurring soon after brain injury. Nevertheless, any acute condition which disturbs the balance between excitatory and suppressing mechanisms may provoke epilepsy, and this may cause a secondary aggravation of the precipitating factor and further development of epilepsy. If the underlying predisposing factor is due to a temporary disturbance of function, then once treatment is effectively instituted restoration of normal function may rapidly take place.

If status is not treated, severe anoxic cerebral and other damage may occur and the patient will remain comatose. Treatment must be started early and aim at effectively suppressing the fits without interfering with consciousness.

\section{Methods of Control}

Because status develops insidiously most patients when first referred have already received large doses of phenobarbitone, or even stupefying doses of paraldehyde. Coma may be due to the epilepsy or medication or both. Apart from excessively heavy sedation, which often is ineffective, the four main methods of controlling these patients are: (1) intravenous lignocaine, (2) intravenous phenytoin sodium, (3) intermittent positive-pressure ventilation, and (4) intravenous thiopentone, which has been in use for the longest time.

\section{Intravenous Lignocaine}

Bernhard and Bohm (1954) showed that intravenous injections of local anaesthetics could diminish or abolish epileptic attacks evoked by electrical cortical stimulation in monkeys.
Experimentally, they showed that lignocaine was less toxic and more effective than procaine or other local anaesthetics tested. Bernhard, Bohm, and Hojeberg (1955) published a report on their successful treatment of 10 patients. They were able to demonstrate a marked synergism between the anti-epileptic barbiturates and lignocaine. The dose of lignocaine varied from 2 to $6 \mathrm{mg}$. $/ \mathrm{kg}$./hour. They claimed that this technique could control status epilepticus without depression of consciousness due to heavy sedating doses of barbiturates. The method was thought to be of value in controlling fits developing early in the postoperative period as it would not mask signs of developing intracranial mischief.

\section{Intravenous Phenytoin Sodium}

The first reported use of parenteral phenytoin sodium for the control of status epilepticus was by Murphy and Schwab (1956), of the Massachusetts General Hospital. They reiterated the danger of using large doses of phenobarbitone which cause coma and respiratory and circulatory depression, and that this could mask signs of a progressively developing lesion. They claimed that phenytoin could suppress the majority of fits yet did not produce respiratory depression or sedative side-effects. Usually 150 to $250 \mathrm{mg}$. intravenously suppressed the fits, but if this was ineffective after half an hour a further 100 to $150 \mathrm{mg}$. might be given.

Satisfactory results in a majority of patients were also reported by Carter (1958) from studies of the inmates of an epileptic colony.

\section{Intermittent Positive-pressure Ventilation}

With the development of intermittent positive-pressure ventilation and the establishment of respiratory failure units, it seemed a logical step to treat patients with status epilepticus by this method, and several anaesthetists reported successful results. Though the method is satisfactory, it is demanding in its requirements for nursing personnel and medical staff, and is the most complicated of the methods described. It really necessitates nursing the patient in an intensive care unit by specially trained staff. As the use of intermittent positivepressure ventilation is familiar to all anaesthetists, it is not described here in detail. Not all patients can be controlled adequately by intermittent positive-pressure ventilation.

\section{Intravenous Thiopentone}

Intravenous thiopentone has scarcely merited more than a passing mention in the world literature, yet it is probably the most effective and the simplest method of controlling status epilepticus. It has been used for the control of 117 patients during the past 16 years. The suppressing dose of thiopentone is extremely small-much smaller than the normal sleep dose.

\footnotetext{
* Consultant Anaesthetist, Department of Surgical Neurology, the Royal Infirmary and Western General Hospital, Edinburgh.
} 
Consequently the anti-epileptic dose has no significant effect on consciousness. Because the action of a single dose is evanescent, thiopentone must be given as a continuous infusion to achieve the necessary degree of control.

An initial intravenous dose of 25 to $100 \mathrm{mg}$. is given slowly until convulsions cease. The intravenous drip is then set up with a fine catheter which will limit the maximum flow rate. Thiopentone, $1 \mathrm{~g}$., is dissolved in $550 \mathrm{ml}$. of Ringer lactate solution and the infusion started at the rate of $1 \mathrm{ml}$. a minute. If fits remain absent for half an hour the dose is reduced by $50 \%$. Usually about $1 \mathrm{~g}$. is required during the first 12 hours. Occasionally as much as $2 \mathrm{~g}$. may be necessary, or $0.5 \mathrm{~g}$. may suffice.

The fine catheter limits the maximum rate of infusion and prevents accidental overdosage even if the drip is carelessly turned full on.

The average duration of treatment for an adult is 48 hours, but varies from 24 to 72 hours. Once fits are suppressed, postictal coma rapidly passes and the patient regains consciousness so that he can behave in the ward as normally as his lesion permits. A deterioration in the level of consciousness is usually due to a return of epilepsy and so an indication for more thiopentone, and not an indication that too much thiopentone has been given.

Out of 117 patients treated by thiopentone infusion, only two required the infusion to be continued for longer than 72 hours. One patient ultimately died after three weeks' treatment, from a rapidly growing highly malignant glioma infiltrating the basal ganglion and both cerebral hemispheres. The other was a child who was not satisfactorily controlled by intermittent positivepressure ventilation and was treated by thicpentone for seven days. The youngest patient treated was 6 months and the oldest an octogenarian. No side-effects or difficulties of management were encountered in any patient.

\section{Discussion}

An attempt was made to evaluate the other major methods as they were reported. During 195510 patients were treated with intravenous lignocaine, with only limited success. All were very severe fulminating traumatic or postoperative cases and, though the severity and intensity of the attacks were modified, full control was not achieved at dose levels as high as $6 \mathrm{mg}$./ kg./hour. Each of the 10 patients had already received moderate doses of intramuscular phenobarbitone before the lignocaine infusion was started.

Though a considerable degree of control could be achieved, continuous regulation of the drip was required to obtain fairly satisfactory results. After about four hours in the most favourable or as little as an hour in the worst cases, lignocaine therapy was abandoned and thiopentone substituted, with complete satisfaction and ease of control.

Seven patients received phenytoin sodium. The youngest was 6 months of age. Though fits could be modified or tem- porarily suppressed, continuous suppression was difficult to achieve in our severely ill patients. Because of difficulties in management, the method was abandoned in each case and thiopentone successfully substituted. Very severe angiospasm affecting one lower limb followed the intravenous infusion of dilute phenytoin into the baby's long saphenous vein and caused much anxiety for several hours.

Intermittent positive-pressure ventilation was used for five patients who already had had tracheostomy performed. Though the method worked well in four cases, it was considered that the results obtained were certainly no better than those with thiopentone. However, very much greater effort was required from the nursing and medical staff to achieve such a result, and the need for complete relaxation and sedation tended to mask the progress of neurological disease. If we had encountered a patient refractory to treatment with thiopentone, then we would certainly have employed this method again, but the need has never arisen. One child was difficult to control, and in spite of the complete suppression of fits began to deteriorate after five days. Intermittent positive-pressure ventilation was discontinued and thiopentone substituted without difficulty. Within hours the patient's general and neurological condition started to improve and a full recovery was made after seven days' treatment.

\section{Summary}

The control of status epilepticus with thiopentone is extremely safe, certain, and easy when used correctly, and imposes no additional hazard to the patient or load on the nursing staff. It does not complicate the observation or management of the patient's neurological condition, and is the method that has been employed by us and our staff during the past 16 years. It is a method that has never failed and has been used to control patients who have been refractory to other forms of drug therapy. It has no significant effect on the patient's level of consciousness.

Drugs such as paraldehyde are very unsatisfactory, often failing to achieve any control even in stupefying doses, and should be avoided.

We wish to acknowledge the co-operation and assistance of our surgical colleagues in the department of surgical neurology who have now adopted intravenous thiopentone infusion as the most satisfactory method of controlling status epilepticus. We wish to thank Professor N. M. Dott, Professor John Gillingham, Mr. P. Harris, and Mr. J. F. Shaw, whose patients provided material for this study.

REFERENCES

Bernhard, C. G., and Bohm, E. (1954). Acta physiol. scand., 31, 104. Carter, C. H. (1958). Ibid., 79, 136.

Murphy, J. T., and Schwab, R. S. (1956). f. Amer. med. Ass., 160,

Russell, W. R., and Whitty, C. W. M. (1952). F. Neurol. Neurosurg. Psychiat., 15, 93. 